\title{
Alianças Estratégicas e Vantagens Competitivas: Uma Abordagem Teórico-Empírica sob a ótica da Visão Baseada em Recursos
}

\author{
Nágila Giovanna Silva VILELA
}

Faculdade de Economia, Administração e Contabilidade da Universidade de São Paulo (FEA/USP), São Paulo, SP, Brasil

\section{Ronaldo de Oliveira SANTOS JHUNIOR}

Faculdade de Economia, Administração e Contabilidade da Universidade de São Paulo (FEA/USP) São Paulo, SP, Brasil

\author{
Received 18 Mar. 2018; Accepted 1 Jun. 2018 \\ Evaluation System: Double Blind-Review \\ Editor: Jose Lindenberg Julião Xavier Filho, Dr. \\ ISSN: 2594-8040
}

To cite this paper: Vilela, N. G. S., \& Santos Jhunior, R. O. (2018). Alianças estratégicas e vantagens competitivas: Uma abordagem teórico-empírica sob a ótica da Visão Baseada em Recursos. Journal of Perspectives in Management - JPM, 2(1), p. 21-31.

\section{Resumo}

O objetivo deste artigo se pautou em observar as consequências práticas de alianças estratégicas e sua capacidade de geração de vantagens competitivas em diferentes campos de atuação empresarial. Para isso, foram analisadas, além de pesquisas para fundamentação teórica, artigos de cunho empírico da literatura nacional. A perspectiva da Visão Baseada em Recursos considera que quando firmas se associam em alianças, o propósito é que o desempenho e produtividade de cada uma das partes sejam maximizados. A partir da discussão apresentada percebeu-se que diferentes tipos de alianças estratégicas podem influenciar no desempenho e otimização de vantagem competitiva de formas variadas.

Palavras-Chave: Alianças Estratégicas; Visão Baseada em Recursos; Vantagens Competitivas. 


\section{Introdução}

Partindo do pressuposto da importância a respeito do desenvolvimento e sustentabilidade de vantagens competitivas no cenário multifacetado e competitivo existente desde meados do século XX, o objetivo do presente trabalho é observar as consequências práticas de alianças estratégicas e sua capacidade de geração de vantagens competitivas em diferentes campos de atuação empresarial.

As alianças geralmente se formam quando empresas se encontram em uma posição estratégica vulnerável, seja pelo fato de estarem competindo em ambientes emergentes ou de indústrias com elevado poder de competitividade ou pelo fato de estarem se empenhando em estratégias pioneiras (Eisenhardt \& Schoonhoven, 1996). As autoras também argumentam que alianças se formam quando empresas estão em posições sociais fortalecidas pelo fato de estarem sendo lideradas por grandes, experientes e bem conectadas equipes de alta gestão. A lógica de formação de aliança é, então, necessidade estratégica e oportunidade social (Eisenhardt \& Schoonhoven, 1996).

Ao considerar a visão baseada em recursos (VBR) para compreensão da lógica de formação de alianças estratégicas, tem-se que o estabelecimento das mesmas é uma questão crucial para muitas empresas contemporâneas (Eisenhardt \& Schoonhoven, 1996). Tais relacionamentos cooperativos na lógica de alianças podem ajudar as empresas a conservar recursos e compartilhar os riscos existentes no contexto em que estão inseridas (Hamel, Doz, \& Prahalad, 1989; Eisenhardt \& Schoonhoven, 1996). Baum e Oliver (1991) destacam que alianças também podem servir como sinais de avanços em legitimidade para empresas e conforme pensado por Hagedoorn (1993), Hamel et al. (1989) e Hennart (1998) - como oportunidades para ganhar novas competências e poder de mercado.

Em uma maior evidência das possibilidades de estudo e influência da VBR no que se refere à lógica de aliança estratégica, Vale e Lopes (2010) argumentam, com base em Ambrosini e Bowman (2009), que a perspectiva das capacidades dinâmicas, a qual ampliou a VBR, vem, desde a década de 1990, avançando consideravelmente. Dessa forma, é possível observar que a literatura na área de estudos estratégicos mostra como as alianças podem ser visualizadas como geradoras de capacidade dinâmica, à medida que possibilitam a renovação e a reconfiguração dos recursos empresariais (Vale \& Lopes, 2010) e o desenvolvimento de vantagens competitivas sustentadas.

Este trabalho está dividido em cinco tópicos principais: o primeiro refere-se à introdução; o segundo apresenta o referencial teórico a respeito da visão baseada em recursos e alianças estratégicas e desempenho; o terceiro trata dos procedimentos metodológicos adotados na pesquisa; o quarto apresenta os resultados e as discussões e, por último, o quinto tópico contém as considerações finais.

\section{Referencial Teórico}

Este tópico consiste em fundamentar o tema abordado na pesquisa e está dividido em dois subtópicos: visão baseada em recursos (VBR) e aliança estratégica e desempenho.

\subsection{Visão Baseada em Recursos (VBR)}

Em administração estratégica, a questão central pesquisada refere-se ao porquê algumas organizações superam outras. Enquanto a teoria dos custos de transação e a teoria da agência, por exemplo, consideram as firmas homogêneas, o paradigma estrutura-conduta-desempenho (SCP) e a VBR qualificam as organizações como heterogêneas (Barney \& Hesterly, 2004).

As críticas ao paradigma estrutura-condutadesempenho surgem no sentido que ao afirmar que o ramo é a razão do desempenho da organização, os ramos são caracterizados como homogêneos. Porém, a diversidade é maior em ramos singulares que em outros distintos (Barney \& Hesterly, 2004). Em contrapartida, a perspectiva da VBR é que as firmas obtêm vantagem competitiva sustentada quando intensificam suas forças internas em resposta às oportunidades do mercado, contêm fraquezas internas e diminuem as ameaças do ambiente (Barney, 1991).

O termo visão baseada em recursos foi proposto inicialmente por Wernerfelt (1984). O autor deixa de analisar a firma com base em seus produtos e analisa-a quanto aos recursos. "Um recurso denota qualquer coisa que possa ser pensado como uma força ou fraqueza de uma determinada empresa" (Wernerfelt, 1984, p. 172). Essa percepção de reconhecer a firma como um agrupamento de recursos remonta à ideia de Penrose (2006). Para a mesma, a firma não é apenas uma unidade administrativa, mas também um agrupamento de recursos produtivos. $\mathrm{O}$ arranjo desses recursos assim 
como sua utilização é estabelecido por decisões administrativas. Por essa razão a autora considera que o tamanho de uma empresa pode ser mensurado quando é considerada a proporção dos recursos usados (Penrose, 2006).

A heterogeneidade das firmas e imobilidade dos recursos são os dois pressupostos básicos presentes na VBR (Barney \& Hesterly, 2004). O conceito chave dessa perspectiva é que a vantagem competitiva sustentada pode ser alcançada através da aplicação de recursos e capacidades quando esses são valiosos, raros, inimitáveis e não substituíveis. É importante destacar que a posse de recursos com tais características não é por si só sinônimo de vantagem, mas a capacidade de integrá-los e desenvolvê-los é que gera tal vantagem (Barney, 1991).

A VBR relaciona-se com diversas áreas do conhecimento e 20 após o trabalho de Barney (1991), a também denominada teoria baseada em recursos é "[...] amplamente reconhecida como uma das teorias mais importantes e poderosas para descrever, explicar e predizer relações organizacionais" (Barney, Ketchen \& Wright, 2011, p. 1300).

Conquistar e manter vantagem competitiva sustentada, para uma única empresa, pode ser praticamente impossível quando se considera a utilização de recursos em ambientes instáveis e dinâmicos (D'aveni, Dagnino \& Smith, 2010). A união/aliança de duas ou mais organizações, entretanto, pode propiciar o alcance e preservação desse tipo de vantagem. A relação entre aliança/cooperação e desempenho é discutida no próximo tópico.

\subsection{Aliança Estratégica e Desempenho}

As organizações podem cooperar umas com as outras tanto por meio de acordos implícitos (envolve cartéis e conluios) quanto por alianças estratégicas (Barney \& Hesterly, 2004). Em acordos implícitos as firmas concordam em reduzir a produção de produtos e serviços e aumentar os preços. Com a restrição da oferta e estabilidade da demanda, os preços sobem. As alianças estratégicas, por outro lado, ocorrem com mais frequência que os cartéis.

Nesses casos, o bem-estar social não é diminuído. Uma aliança estratégica pode ser de dois tipos: contratual ou joint venture. No primeiro caso, as organizações firmam contratos para coordenar a relação e o objetivo é aumentar as atividades econômicas das empresas pactuadas; em joint ventures uma nova organização é criada a partir da aliança (Barney \& Hesterly, 2004).

Teece (1992, p. 467) define aliança estratégica como " $[\ldots]$ uma constelação de acordos caracterizados pelo compromisso de duas ou mais empresas parceiras para atingir um objetivo comum, o que implica a partilha dos seus recursos e atividades". É necessário haver alguma coordenação estratégica e operacional e pode incluir atividades como acordos de cooperação de marketing, pesquisa e desenvolvimento e compra exclusiva (Teece, 1992).

Nesse mesmo sentido, a definição proposta por Gulati (1998) refere-se a alianças estratégicas como acordos espontâneos entre organizações com o propósito de troca, divisão ou desenvolvimento cooperativo de recursos, seja na forma de produtos, serviços ou tecnologias.

Até 1980 a concorrência entre as organizações não era um grande problema e essas não precisavam necessariamente adquirir capacidades para tornaremse diferenciadas. As mudanças não ocorriam com muita frequência e as empresas não se importavam em unir com outras organizações para obter e aprimorar competências. Existiam, portanto, poucas alianças estratégicas entre as firmas (Harbison \& Pekar, 1999 apud Del Corso, Silva \& Sandrini, 2005).

Com a globalização e o avanço tecnológico é necessário que as empresas estejam atuantes nos principais mercados, com alta produtividade e custo reduzido, além disso, esperam-se trabalhadores qualificados e novas tecnologias sendo desenvolvidas continuamente. Atender a todos esses requisitos pode ser oneroso demais para as organizações, levando-as a adotar estratégias de parceria como forma de sobreviver e aumentar a competitividade (Klotzle, 2002). Assim, independentemente do tipo de aliança estratégica adotada, o objetivo das partes é aprimorar uma vantagem cooperativa que influencie positivamente no desempenho individual e coletivo dos envolvidos (Eiriz, 2001)

Nessa perspectiva, alguns fatores críticos para uma aliança de sucesso podem ser numerados: (1) clareza no objetivo estratégico, o que significa que mais importante que a aliança em si, é a estratégia que se encontra por trás dela; (2) busca por um parceiro apropriado, isto é, com objetivos conciliáveis e competências complementares; (3) distribuição de tarefas e responsabilidades para as partes envolvidas na aliança; (4) criação de estímulos para a cooperação; (5) comunicação eficaz e contato pessoal, de maneira que a confiança entre os parceiros seja estabelecida; (6) planejamento de longo prazo; (7) desenvolvimento de projetos em 
conjunto; e (8) flexibilidade (Gomes-Casseres, 1999).

As firmas, portanto, buscam se envolver em alianças estratégicas de sucesso visando obter melhores resultados. O propósito é que ao entrar em parcerias, a performance do grupo seja maior do que seria atingida se cada uma das partes trabalhasse independentemente (Garcias, 2001). Assim, a formação de alianças objetiva rendimentos superiores individuais e coletivos a partir das ações recíprocas dos membros (Garcias, 2001). A fim de propiciar maior entendimento a respeito dos temas abordados, na seção de discussões são apresentados os impactos causados por alianças estratégicas na vantagem competitiva de algumas empresas com base em estudos empíricos.

\section{Metodologia}

Objetivando ampliar o entendimento a respeito do impacto das alianças estratégicas no desenvolvimento de vantagens competitivas sustentadas, este artigo buscou abarcar os principais pensadores ligados a temas relacionados à visão baseada em recursos. Trata-se, portanto, de uma pesquisa qualitativa. Essa é uma abordagem que busca compreender e detalhar diferentes aspectos relacionados aos fenômenos de maneira aprofundada (Gibbs, 2009).

Foram realizadas pesquisas buscando trabalhos de cunho empírico nas seguintes bases de dados: Periódicos Capes, Google Acadêmico, Scientific Electronic Library Online (SciELO) e eventos da Associação Nacional de Pós-Graduação e Pesquisa em Administração (ANPAD). Nessa última (ANPAD), foram analisados os resumos dos artigos e sua compatibilidade com os objetivos da pesquisa. Nas demais bases, os termos "vantagem competitiva" e "aliança estratégica" foram utilizados em conjunto, isto é, apenas consideraram-se os artigos que continham ambos os tópicos em qualquer parte do texto. Além disso, vale ressaltar que somente artigos da área de Administração foram levados em conta.

Como resultado dessa busca, foram encontrados 17 artigos que se enquadravam na proposta desta pesquisa. Estes estavam situados em um espaço temporal dos últimos 15 anos e continham variados aportes metodológicos e pesquisas amostrais. Os trabalhos empíricos foram analisados com o objetivo de obter maior compreensão da realidade prática das alianças estratégicas e seu impacto no desenvolvimento de vantagens competitivas.
Tais trabalhos, apresentados na discussão a seguir, oferecem uma melhor visualização de como as alianças estratégicas podem impactar nas vantagens competitivas dentro da lógica empresarial.

\section{Discussões}

O objetivo desse trabalho é observar as consequências práticas de alianças estratégicas e sua capacidade de geração de vantagens competitivas em diferentes campos de atuação empresarial. Para tal, com base na literatura já apresentada nos tópicos anteriores e em alguns artigos empíricos (Figura 1), serão discutidos os impactos das alianças estratégicas selecionadas para análise.

De acordo com a literatura, empresas participam de alianças estratégicas visando obter resultados superiores aos que conseguiriam quando trabalham de forma isolada (Eiriz, 2001; Garcias, 2001). No entanto, essas alianças podem gerar resultados adversos, devido a fatores como: não entendimento da estratégia por uma das partes, comunicação ineficaz, escolha de parceiros com objetivos distintos, entre outros (Gomes-Casseres, 1999).

Em relação às alianças estratégicas, observa-se que pode haver dificuldades na obtenção de vantagem competitiva. A alta competitividade e o comportamento individualista são exemplos de situações que dificultam as parcerias entre concorrentes (Hocayen-da-Silva \& Teixeira, 2009). Em alianças como franquias, convênios próprios e terceirizados, fornecedores exclusivos, associações independentes e alianças de compras com outras empresas, o grande número de normas e regras pode ocasionar em problemas para as partes. Tais problemas podem incluir: perda de parte da autonomia, falta de agilidade, lentidão do processo de decisão e complexidade organizacional, não geração de lucros imediatos e risco de inadimplência (Ribeiro \& Prieto, 2013).

Apesar das possíveis desvantagens e impactos negativos ocasionados por alianças estratégicas, as oportunidades de benefícios e vantagem competitiva são amplas. Quando há clareza no objetivo estratégico, comunicação eficaz e distribuição de responsabilidades, as alianças possuem altas chances de serem bem-sucedidas (Gomes-Casseres, 1999). Tais itens são relevantes, pois, ao associarem-se em acordos estratégicos, as firmas estão em busca do desenvolvimento de habilidades e competências (Eiriz, 2001; Garcias, 2001). 
Alianças Estratégicas e Vantagens Competitivas: Uma Abordagem Teórico-Empírica sob a ótica da Visão Baseada em Recursos

Quadro 1 - Artigos empíricos que tratam de alianças estratégicas e vantagem competitiva

\begin{tabular}{|c|c|c|c|c|}
\hline Estudo & Objetivo & Amostra & Metodologia & $\begin{array}{c}\text { Impacto da aliança estratégica na vantagem } \\
\text { competitiva }\end{array}$ \\
\hline Galerani (2003) & $\begin{array}{c}\text { Estudar uma integração vertical estabelecida } \\
\text { entre cooperativas agropecuárias, em suas } \\
\text { etapas de formação, estruturação e } \\
\text { implementação }\end{array}$ & $\begin{array}{l}\text { Cooperativa Agropecuária } \\
\text { de Londrina Ltda. (Cativa) } \\
\text { e Cooperativa Central } \\
\text { Agro-industrial Ltda. } \\
\text { (Confepar) }\end{array}$ & Estudo de caso & $\begin{array}{l}\text { Otimização da estrutura; obtenção de escala de } \\
\text { produção; compartilhamento de atividades; fim da } \\
\text { competição entre as cooperativas; utilização, em } \\
\text { conjunto, de marcas; acesso a recursos financeiros } \\
\text { e utilização, em comum, de tecnologias }\end{array}$ \\
\hline $\begin{array}{l}\text { Tauhata \& Macedo- } \\
\quad \text { SoareS (2004) }\end{array}$ & $\begin{array}{l}\text { Evidenciar a importância de levar em conta na } \\
\text { gestão estratégica de empresas que atuam em } \\
\text { redes de alianças as implicações destas redes } \\
\text { para sua conduta e desempenho }\end{array}$ & Cia Vale do Rio Doce & $\begin{array}{l}\text { Estudo de caso com } \\
\text { base em pesquisa } \\
\text { bibliográfica, } \\
\text { documental e de campo }\end{array}$ & $\begin{array}{l}\text { Maior sucesso nas estratégias, fortalecendo os } \\
\text { relacionamentos com os vários atores estratégicos } \\
\text { que compõem a rede de valor, alavancando-a } \\
\text { como fonte de informação sobre oportunidades e } \\
\text { ameaças, acelerando a tomada de decisão e } \\
\text { reduzindo as barreiras à entrada em outros } \\
\text { mercados }\end{array}$ \\
\hline $\begin{array}{l}\text { Manãs \& Pacanhan } \\
\text { (2004) }\end{array}$ & $\begin{array}{l}\text { Abordar os conceitos de alianças estratégicas e } \\
\text { redes associativistas, suas vantagens e } \\
\text { desvantagens e seu uso no varejo }\end{array}$ & $\begin{array}{l}\text { Rede composta de } \\
\text { pequenos varejistas na área } \\
\text { de material de construção } \\
\text { formada inicialmente na } \\
\text { cidade de Maringá (PR) }\end{array}$ & $\begin{array}{c}\text { Estudo exploratório com } \\
\text { análise de casos }\end{array}$ & $\begin{array}{l}\text { Compartilhamento de elementos da cadeia de } \\
\text { valor. Principal dificuldade: dualidade entre } \\
\text { competição e cooperação }\end{array}$ \\
\hline Del Corso et al. (2005) & $\begin{array}{c}\text { Verificar, em termos práticos, se realmente } \\
\text { existem alianças estratégicas firmadas entre } \\
\text { clientes e fornecedores, e se estas geram } \\
\text { vantagens competitivas }\end{array}$ & Electrolux do Brasil & $\begin{array}{l}\text { Estudo de caso de } \\
\text { natureza exploratória }\end{array}$ & $\begin{array}{c}\text { As alianças estratégicas geram vantagens } \\
\text { competitivas não só para o cliente, mas para } \\
\text { ambos os lados envolvidos }\end{array}$ \\
\hline Souza \& Baldin (2005) & $\begin{array}{l}\text { Analisar algumas características das } \\
\text { cooperativas de leite no Brasil e as dificuldades } \\
\text { competitivas enfrentadas por esse segmento } \\
\text { integrante da cadeia leiteira }\end{array}$ & $\begin{array}{l}\text { Setor cooperativista leiteiro } \\
\text { na produção nacional }\end{array}$ & $\begin{array}{l}\text { Discussão teórica } \\
\text { conceitual }\end{array}$ & $\begin{array}{c}\text { Elevação do nível de competitividade, mediante o } \\
\text { do desenvolvimento de economias de escala, } \\
\text { aumento de produtividade, regularidade da } \\
\text { produção, maior qualidade dos produtos e uma } \\
\text { estratégia mercadológica }\end{array}$ \\
\hline $\begin{array}{l}\text { Ferreira \& Barcellos } \\
\qquad(2006)\end{array}$ & $\begin{array}{l}\text { Analisar as vantagens e desvantagens das } \\
\text { alianças em cadeias agroindustriais, a partir da } \\
\text { percepção dos agentes participantes de uma } \\
\text { aliança específica estabelecida na cadeia da } \\
\text { carne bovina }\end{array}$ & $\begin{array}{l}\text { Empresa varejista, indústria } \\
\text { frigorífica e associação de } \\
\text { produtores de raça }\end{array}$ & $\begin{array}{l}\text { Pesquisa exploratória } \\
\text { por meio de estudo de } \\
\text { caso }\end{array}$ & $\begin{array}{c}\text { Diferenciação do produto, o acesso ao mercado e } \\
\text { a maior estabilidade na produção }\end{array}$ \\
\hline
\end{tabular}




\begin{tabular}{|c|c|c|c|c|}
\hline \multicolumn{5}{|l|}{... continuação } \\
\hline Pacagnan (2006) & $\begin{array}{l}\text { Identificação do processo de constituição de } \\
\text { alianças estratégicas horizontais }\end{array}$ & $\begin{array}{l}\text { Uma rede de } \\
\text { supermercados e uma rede } \\
\text { de materiais de construção }\end{array}$ & $\begin{array}{c}\text { Estudo exploratório com } \\
\text { análise de casos }\end{array}$ & $\begin{array}{l}\text { Aquisição de maior competitividade e } \\
\text { incorporação de novas competências. Obstáculos: } \\
\text { perda de identidade ou o nivelamento de parte da } \\
\text { concorrência setorial }\end{array}$ \\
\hline $\begin{array}{l}\text { Nohara, Campanário; } \\
\text { Margarido \& Acevedo } \\
\text { (2007) }\end{array}$ & $\begin{array}{l}\text { Entender a razão das MPEs adotarem uma } \\
\text { estratégia colaborativa na atividade exportadora }\end{array}$ & Consórcios de exportação & $\begin{array}{c}\text { Pesquisa de casos } \\
\text { múltiplos, com enfoque } \\
\text { exploratório e natureza } \\
\text { qualitativa }\end{array}$ & $\begin{array}{l}\text { Superação dos principais entraves à exportação } \\
\text { individual por meio dos consórcios de exportação }\end{array}$ \\
\hline $\begin{array}{l}\text { Mattana, Noro \& } \\
\text { Estrada (2008) }\end{array}$ & $\begin{array}{c}\text { Caracterizar uma aliança estratégica e o seu } \\
\text { processo de formação }\end{array}$ & $\begin{array}{l}\text { Empresas FEMSA e CVI } \\
\text { Refrigerantes Ltda }\end{array}$ & $\begin{array}{l}\text { Estudo de caso com } \\
\text { técnica qualitativa }\end{array}$ & $\begin{array}{c}\text { Elevação do negócio e maior estabilidade nas } \\
\text { estratégias }\end{array}$ \\
\hline $\begin{array}{l}\text { Barbosa, Zilber } \\
\text { \&Toledo (2009) }\end{array}$ & $\begin{array}{l}\text { Discutir as características das alianças } \\
\text { estratégicas e demonstrar para as empresas não } \\
\text { participantes desse tipo de arranjo cooperativo } \\
\text { os benefícios que podem decorrer dessa relação }\end{array}$ & $\begin{array}{l}121 \text { empresas, de portes } \\
\text { diversos, distribuídas por } \\
\text { vários Estados do Brasil }\end{array}$ & $\begin{array}{c}\text { Caráter exploratório por } \\
\text { meio de pesquisa de } \\
\text { campo }\end{array}$ & $\begin{array}{c}\text { Enfoque em ganhos mútuos, organização } \\
\text { administrativa, comprometimento e cooperação } \\
\text { para a obtenção de uma posição mais forte sem } \\
\text { que ocorram perdas }\end{array}$ \\
\hline $\begin{array}{l}\text { Hocayen-Da-Silv \& } \\
\text { Teixeira (2009) }\end{array}$ & $\begin{array}{c}\text { Analisar os relacionamentos } \\
\text { interorganizacionais realizados por empresas } \\
\text { hoteleiras de Curitiba }\end{array}$ & Dois hotéis de Curitiba & Estudo de casos & $\begin{array}{l}\text { Não há união entre os hotéis para criar barreiras } \\
\text { de entrada e proteger o mercado. No entanto, } \\
\text { alguns poucos relacionamentos resultam em } \\
\text { redução de custos na compra de insumos e na } \\
\text { divulgação e propaganda das organizações }\end{array}$ \\
\hline $\begin{array}{l}\text { Fetter \& Zdanowicz } \\
\qquad(2013)\end{array}$ & $\begin{array}{c}\text { Analisar o processo de planejamento estratégico } \\
\text { em micro e pequenas empresas que atuam em } \\
\text { alianças ou redes na cidade de Três Coroas, no } \\
\text { Estado do Rio Grande do Sul }\end{array}$ & $\begin{array}{l}\text { Empresários do ramo } \\
\text { varejista que participam } \\
\text { redes colaborativas na } \\
\text { cidade de Três Coroas (RS) }\end{array}$ & Estudo de caso coletivo & $\begin{array}{c}\text { Possibilidade de compras coletivas, uma vez que } \\
\text { possibilita às empresas maior poder de barganha, } \\
\text { acesso a melhores preços e condições de } \\
\text { pagamento }\end{array}$ \\
\hline Ribeiro \& Prieto (2013) & $\begin{array}{c}\text { Ampliar a compreensão do movimento } \\
\text { competitivo que tem se desenvolvido no varejo } \\
\text { farmacêutico; identificar os tipos de alianças } \\
\text { estratégicas praticadas pelo varejo } \\
\text { farmacêutico, bem como as principais } \\
\text { vantagens e desvantagens decorrentes desse } \\
\text { processo }\end{array}$ & $\begin{array}{l}\text { Farmácias e drogarias } \\
\text { localizadas nas cidades de } \\
\text { Bragança Paulista e } \\
\text { Atibaia, pertencentes à } \\
\text { Região Bragantina, no } \\
\text { Estado de São Paulo }\end{array}$ & $\begin{array}{l}\text { Método qualitativo de } \\
\text { pesquisa com coleta de } \\
\text { dados por meio de } \\
\text { entrevistas }\end{array}$ & $\begin{array}{l}\text { Não foram identificadas barreiras de entrada ou } \\
\text { vantagens competitivas específicas. Os gestores } \\
\text { concordam com a afirmação teórica de que a } \\
\text { formação de alianças agrega valor às atividades } \\
\text { da farmácia ou drogaria, proporciona maior } \\
\text { acesso ao mercado e rápido crescimento }\end{array}$ \\
\hline
\end{tabular}




\begin{tabular}{|c|c|c|c|c|}
\hline \multicolumn{5}{|l|}{... continuação } \\
\hline $\begin{array}{l}\text { Fischer, Rover, } \\
\text { Fransozi \& Mello } \\
\qquad(2014)\end{array}$ & $\begin{array}{c}\text { Analisar o desempenho das empresas } \\
\text { constituintes da Rede Oeste de Cooperação de } \\
\text { Empresas Contábeis de SC buscando } \\
\text { caracterizar cada empresa, identificando os } \\
\text { objetivos, as ações de gestão e a percepção dos } \\
\text { sócios em relação aos benefícios obtidos pelo } \\
\text { sistema de redes }\end{array}$ & $\begin{array}{l}\text { Cinco empresas contábeis, } \\
\text { localizadas nos municípios } \\
\text { de Caçador, Catanduvas, } \\
\text { Concórdia, Joaçaba e } \\
\text { Tangará, em Santa Catarina }\end{array}$ & $\begin{array}{l}\text { Pesquisa de campo } \\
\text { complementada com a } \\
\text { pesquisa bibliográfica e } \\
\text { documental }\end{array}$ & $\begin{array}{l}\text { Realizações de acordos empresariais que se } \\
\text { efetivam em melhores condições do que aquelas } \\
\text { realizadas individualmente para cada uma das } \\
\text { organizações da rede, compartilhamento de } \\
\text { informações e experiências, aperfeiçoamento e } \\
\text { otimização de procedimentos e adoção de novas } \\
\text { estratégias administrativas }\end{array}$ \\
\hline $\begin{array}{l}\text { Braga, Ferraz \& Lima } \\
\text { (2014) }\end{array}$ & $\begin{array}{c}\text { Analisar a formação de joint-ventures, } \\
\text { entendendo como diferentes países relacionam- } \\
\text { se dentro desta aliança estratégica }\end{array}$ & $\begin{array}{l}\text { Duas multinacionais da } \\
\text { indústria automobilística da } \\
\text { Serra Gaúcha }\end{array}$ & $\begin{array}{l}\text { Estudo de casos } \\
\text { múltiplos, qualitativo e } \\
\text { exploratório }\end{array}$ & $\begin{array}{l}\text { Vantagem para ambas as sócias que somam seus } \\
\text { recursos para entrar em novos mercados }\end{array}$ \\
\hline $\begin{array}{l}\text { Tavares, Oliveira, } \\
\text { Balsan \& Moura (2015) }\end{array}$ & $\begin{array}{l}\text { Verificar os ganhos organizacionais obtidos por } \\
\text { PMEs nos primeiros meses de formação de uma } \\
\text { rede de cooperação interorganizacional }\end{array}$ & $\begin{array}{l}\text { Rede Solazer de parques e } \\
\text { balneários }\end{array}$ & $\begin{array}{l}\text { Estudo de caso } \\
\text { descritivo }\end{array}$ & $\begin{array}{l}\text { Importância do processo de troca de informações, } \\
\text { busca de inovação e novas tecnologias }\end{array}$ \\
\hline $\begin{array}{l}\text { Sanematsu, Silva \& } \\
\quad \text { Vieira (2016) }\end{array}$ & $\begin{array}{c}\text { Analisar diferentes abordagens de aliança } \\
\text { estratégica entre fabricante e varejista durante o } \\
\text { período de } 1995 \text { a } 2015 \text {, sob a perspectiva do } \\
\text { fabricante }\end{array}$ & $\begin{array}{l}\text { Empresa fabricante de } \\
\text { filtros de reposição para } \\
\text { automóveis, caminhões, } \\
\text { colheitadeiras, motocicleta, } \\
\text { ônibus, tratores, máquinas e } \\
\quad \text { equipamentos }\end{array}$ & $\begin{array}{l}\text { Entrevista baseada em } \\
\text { roteiro semiestruturado } \\
\text { e análise documental }\end{array}$ & $\begin{array}{l}\text { O foco na abordagem de suporte, relacionamento } \\
\text { e confiança, além do objetivo de vincular as } \\
\text { organizações de forma duradora e substancial, } \\
\text { gerou vantagem competitiva pela aliança } \\
\text { estratégica dentro do canal de marketing entre } \\
\text { fabricante e varejista, e vice-versa }\end{array}$ \\
\hline
\end{tabular}


Gofredo e Bataglia (2015) destacam que a rotina de aprendizagem é a principal vantagem no processo de alianças estratégicas. A partir dela é que novos conhecimentos são gerados. Nos estudos empíricos analisados essa importância de transmissão de conhecimento é considerada como impacto positivo na vantagem competitiva nos trabalhos de Fischer et al. (2014) e Tavares et al. (2015). Dessa forma, o compartilhamento de informações e experiências é fator relevante para o desenvolvimento de vantagem competitiva sustentada.

O benefício da inovação e melhoria contínua (Garcias, 2001) pode ser observado na utilização, em comum, de tecnologias (Galerani, 2003); regularidade da produção e maior qualidade dos produtos (Souza \& Baldin, 2005); diferenciação do produto (Ferreira \& Barcellos, 2006); aperfeiçoamento e otimização de procedimento (Fischer et al., 2014); e busca de inovação e novas tecnologias (Tavares et al., 2015).

Fischer et al. (2014) corroboram as afirmações de Eiriz (2001) e Garcias (2001) quando concluem que as alianças são capazes de proporcionar realizações de acordos empresariais que se efetivam em melhores condições de competitividade do que aquelas realizadas de forma individual para cada uma das organizações da rede. As vantagens, portanto, ocorrem para ambas as partes que somam seus recursos para entrar em novos mercados (Tavares et al., 2015). Além disso, quando os aliados se comprometem e cooperam, eles obtêm uma posição mais forte do que teriam sozinhos (Barbosa et al., 2009). Por essa razão é tão importante que - mais que a recompensa financeira - o suporte, o relacionamento e a confiança sejam a base das alianças (Sanematsu et al., 2016).

As alianças devem ser visualizadas como prolongamento de uma organização, intencionando, com frequência integração e harmonia na relação (Sanematsu et al., 2016). Assim, com maior acesso ao mercado, elevação do negócio, estabilidade e sucesso nas estratégias, organizações que se incluem em alianças estratégicas aumentam seu poder de barganha, tendo acesso a melhores preços e condições de pagamento, além de capacidade para aumentar as barreiras à entrada (Ferreira \& Barcellos, 2006; Mattana et al., 2008; Fetter \& Zdanowicz, 2013; Tauhata \& Macedo-Soares, 2004).

\section{Considerações Finais}

A ampliação considerável da VBR revela uma maneira diferente de compreender a lógica empresarial (Ambrosini \& Bowman, 2009). A firma passa a ser considerada não apenas como uma unidade administrativa, mas também como um agrupamento de recursos produtivos (Penrose, 2006). No entanto, o aumento da competitividade no ambiente globalizado das últimas décadas leva as organizações a buscarem o aprimoramento de suas competências e maximização da produtividade de forma mais evidente. Atender a esses requisitos pode ser oneroso demais para as organizações, levando-as a adotar estratégias de parceria e aliança como forma de sobreviver e aumentar a competitividade (Klotzle, 2002).

O objetivo do presente trabalho foi observar as consequências práticas de alianças estratégicas e sua capacidade de geração de vantagens competitivas em diferentes campos de atuação empresarial. A partir da discussão apresentada, observou-se que variados tipos de alianças estratégicas podem influenciar positiva e negativamente no desempenho das partes envolvidas.

Dessa forma, foi observada a importância dos estudos a respeito dos processos de cooperação, uma vez que possibilitam entender o impacto positivo ou negativo de alianças estratégicas no desenvolvimento e manutenção de vantagem competitiva sob a ótica da visão baseada em recursos.

\section{Referências}

Ambrosini, V., \& Bowman, C. (2009). What are dynamic capabilities and are they a useful construct in strategic management? International journal of management reviews, 11(1), 29-49.

Barbosa, A. C., Zilber, A. M., \& Toledo, A. L. (2009). A aliança estratégica como fator de vantagens competitivas em empresas de ti-um estudo exploratório. RAI-Revista de Administração e Inovação, 6(1), 30, 49.

Barney, J. B., \& Hesterly, W. (2004). Economia das organizações: entendendo a relação entre as organizações e a análise econômica. In Clegg, S. R., Hardy, C. \& Nord, W. R. Handbook de estudos organizacionais. São Paulo: Atlas, 3 , 131-179.

Barney, J. B., Ketchen Jr, D. J., \& Wright, M. (2011). The future of resource-based theory: revitalization or decline?. Journal of Management, 37(5), 1299-1315.

Barney, J. (1991). Firm resources and sustained competitive advantage. Journal of Management, 17(1), 99-120. 
Baum, J. A., \& Oliver, C. (1991). Institutional linkages and organizational mortality. Administrative Science Quarterly, 187218.

Braga, G. G. A, Ferraz, S. F. S., \& de Lima, T. C. B. (2014). Contribuições da aliança estratégica na indústria automobilística: um estudo comparativo. RECADM, 13(2), 250-266.

D'Aveni, R. A., Dagnino, G. B., \& Smith, K. G. (2010). The age of temporary advantage. Strategic Management Journal, 31(13), 1371-1385.

Del Corso, J. M., Silva, W. V., \& Sandrini, G. (2005). Alianças estratégicas e vantagem competitiva. REGE. Revista de Gestão USP, 12(4), 17-31.

Eiriz, V. (2001). Proposta de tipologia sobre alianças estratégicas. Revista de administração contemporânea, 5(2), 65-90.

Eisenhardt, K. M., \& Schoonhoven, C. B. (1996). Resource-based view of strategic alliance formation: Strategic and social effects in entrepreneurial firms. Organization Science, 7(2), 136-150.

Ferreira, G. C., \& Barcellos, M. D. (2006). Vantagens e desvantagens das alianças estratégicas: uma análise sob a ótica dos agentes da cadeia produtiva da carne bovina. Organizações Rurais \& Agroindustriais, 8(1), 117-129.

Fetter, M. R., \& Zdanowicz, J. E. (2013). Redes colaborativas e a construção de alianças estratégicas a micro e pequenas empresas varejistas. COLÓQUIO -- Revista do Desenvolvimento Regional - Faccat, 10(1), 121146.

Fischer, A., Rover, A., Fransozi, L. C., \& Mello, M. O. (2014). Aliança estratégica: rede oeste de cooperação de empresas contábeis de Santa Catarina. Revista de Contabilidade do Mestrado em Ciências Contábeis da UERJ, 19(2), 58-78.

Galerani, J. (2003). Formação, estruturação e implementação de aliança estratégica entre empresas cooperativas. RAE-eletrônica, 2(1), 116.

Garcias, P. M. (2001). A lógica de formação de grupos e aliança estratégica de empresas. Tuiuti: Ciência e Cultura, 24, 51-78.

Gibbs, G. (2009). Análise de dados qualitativos: coleção pesquisa qualitativa. Rio de Janeiro: Bookman Editora.
Gofredo, T. R., \& Bataglia, W. (2015). Os mecanismos de sincronização em alianças estratégicas. Revista de Administração da Universidade Federal de Santa Maria, 8(4), 633649.

Gomes-Casseres, B. (1999). Estratégia em primeiro lugar. HSM Management, 3(15), 58-64.

Gulati, R. (1998). Alliances and networks. Strategic Management Journal, 19(4), 293-317.

Hagedoorn, J. (1993). Understanding the rationale of strategic technology partnering: Interorganizational modes of cooperation and sectoral differences. Strategic Management Journal, 14(5), 371-385.

Hamel, G., Doz, Y. L., \& Prahalad, C. K. (1989). Collaborate with your competitors and win. Harvard Business Review, 67(1), 133-139.

Hennart, J. F. (1988). A transaction costs theory of equity joint ventures. Strategic management journal, 9(4), 118-142.

Hocayen-da-Silva, A. J., Teixeira, R. M. (2009). Análise dos relacionamentos interorganizacionais em empresas do setor hoteleiro de Curitiba: Estudo comparativo de casos. Revista Brasileira de Pesquisa em Turismo, 3(2), 24-48.

Klotzle, M. C. (2002). Alianças estratégicas: conceito e teoria. Revista de Administração contemporânea, 6(1), 85-104.

Mañas, A., \& Pacanhan, M. (2004). Alianças estratégicas e redes associativistas como fonte de vantagem competitiva no varejo de material de construção. Revista Brasileira de Gestão de Negócios, 6(14), 19-33.

Mattana, L., Noro, G. B., \& Estrada, R. J. S. (2008). Caracterização do processo de formação de alianças estratégicas. Internext, 3(2), 181-198.

Nohara, J. J., Campanário, M. D. A., Margarido, G. L., \& Acevedo, C. R. (2007). Consórcios de exportação-aliança estratégica para micro e pequenas empresas: um estudo multicasos. Anais do Encontro da Associação Nacional dos Programas de Pós-Graduação em Administração. Rio de Janeiro, RJ, Brasil, 31.

Pacagnan, M. N. (2006). Alianças estratégicas e redes colaborativas como alternativa competitiva para o pequeno varejista. REGE. Revista de Gestão USP, 13, 19-30.

Penrose, E. T. (2006). A teoria do crescimento da firma. Editora Unicamp.

Ribeiro, B. B., \& Prieto, V. C. (2013). Alianças estratégicas no varejo farmacêutico: vantagens e 
desvantagens na percepção do gestor. Gestão \& Produção, 20(3), 667-680.

Sanematsu, L. S. A., Silva, A. R., \& Vieira, A. M. (2016). Relação entre fabricante e varejista: um estudo qualitativo comparativo no setor de peças automotivas. Navus: Revista de Gestão e Tecnologia, 6(3), 56-69

Souza, D. B., \& Baldin, C. (2005). O papel das alianças estratégicas na competitividade das cooperativas de leite. Organizações Rurais \& Agroindustriais, 7(3), 324-334.

Tauhata, T. L., Macedo-Soares, T. D., \& Diana, L. D. (2004). Redes e alianças estratégicas no Brasil: caso CVRD. RAE-eletrônica, 3(1), 1-23.

Tavares, C. E. M., de Oliveira, J. H. R., Balsan, L. A. G., \& de Moura, G. L. (2015). Resultados obtidos por pequenas e médias empresas nos primeiros meses de formação de uma rede de cooperação interorganizacional. Revista Pensamento \& Realidade, 30(3), 3-16.

Teece, D. J. (1992). Competition, cooperation, and innovation: Organizational arrangements for regimes of rapid technological progress. In Teece, D. J. Essays in Technology Management and Policy: Selected Papers of David J Teece. World Scientific, 447-474.

Vale, G. M. V., \& Lopes, H. E. G. (2010). Alliances and Cooperation: Theoretical Outlooks in the Realm of Strategic Thought. Revista de Administração Contemporânea, 14(4), 722-737.

Wernerfelt, B. (1984). A resource-based view of the firm. Strategic Management Journal, 5(2), 171180.

\title{
Strategic Alliances and Competitive Advantages: A Theoretical-Empirical Approach from the viewpoint of Resources-Based View
}

\begin{abstract}
The objective of this article was to observe the practical consequences of strategic alliances and their capacity to generate competitive advantages in different fields of business activity. To do so, we analyzed, in addition to research for theoretical basis, empirical articles of the national literature. The Resource Based View perspective considers that when firms partner in alliances, the purpose is to maximize the performance and productivity of each part. From the discussion presented it was realized that different types of strategic alliances can influence the performance and optimization of competitive advantage in various ways.
\end{abstract}

Keywords: Strategic Alliances; Resource-Based View; Competitive Advantages.

\section{Alianzas estratégicas y ventajas competitivas: Un enfoque teórico-empírico desde el punto de vista de la visión basada en recursos}

\section{Resumen}

El objetivo de este artículo se basó en observar las consecuencias prácticas de alianzas estratégicas y su capacidad de generación de ventajas competitivas en diferentes campos de actuación empresarial. Para ello, fueron analizadas, además de investigaciones para fundamentación teórica, artículos de cuño empírico de la literatura nacional. La perspectiva de la Visión Basada en Recursos considera que cuando las firmas se asocian en alianzas, el propósito es que el rendimiento y la productividad de cada una de las partes sean maximizados. A partir de la discusión presentada se percibió que diferentes tipos de alianzas estratégicas pueden influenciar en el desempeño y optimización de ventaja competitiva de formas variadas.

Palabras Clave: Alianzas Estratégicas, Visión Basada en Recursos, Ventajas Competitivas. 


\section{Sobre os Autores}

\section{Nágila Giovanna Silva VILELA}

Mestra em Administração pela Universidade Federal do Paraná (UFPR) e Doutoranda em Administração pela Faculdade de Economia, Administração e Contabilidade da Universidade de São Paulo (FEA/USP)

Avenida Professor Luciano Gualberto - Butantã - São Paulo - SP - Brasil - CEP 05.508-010.

E-mail: nagilavilela@gmail.com

\section{Ronaldo de Oliveira SANTOS JHUNIOR}

Mestre em Administração pela Universidade Federal do Paraná (UFPR) e Doutoranda em Administração pela Faculdade de Economia, Administração e Contabilidade da Universidade de São Paulo (FEA/USP)

Avenida Professor Luciano Gualberto - Butantã - São Paulo - SP - Brasil - CEP 05.508-010.

E-mail: ronaldojhr@gmail.com 